\title{
The Supplementary Education Teacher's Portfolio: Essence, Functions, Structure and Design Principles
}

Regina G. Sakhieva

Academy of Social Education, Kazan, Russia

Email: saxievarg@mail.ru

Larisa V. Majkova

Marina V. Emelyanova

Nelli G. Gavrilova

Evgenia G. Sharonova

Chuvash State Pedagogical University named after I.Y. Yakovlev, Cheboksary, Russia

Albina R. Gatina

Naberezhnye Chelny Institute of Social-Pedagogical Technologies and Resources, Naberezhnye Chelny, Russia

Nailya A. Pavlova

Tatiana A. Baklashova

Kazan (Volga region) Federal University, Kazan, Russia

\section{Doi:10.5901/mjss.2015.v6n2s3p84}

Abstract

The article discloses the contradictions, which define the necessity and possibility to use teacher's portfolio in the system of children's supplementary education. It gives the author's interpretation of the concept "supplementary education teacher's portfolio", defines objectives, the portfolio functions and the principles of its design. The article offers the author's structure of the supplementary education teacher's portfolio, which reflects the main directions of the teacher's professional activities, allows demonstrating the achievements and the results of these activities. The authors describe the alternatives to use the portfolio in supplementary education. The article reveals the risks of portfolio implementation in the institutions of supplementary education. Practical recommendations for the teacher's portfolio development given in the article are practiceoriented. The article addresses the administration and the teachers of the children's supplementary education institutions, the lecturers of the teacher's training colleges, who train future teachers of the supplementary education as well as the educators of the extended education within the process of the professional skills improvement for supplementary education teachers.

Keywords: a supplementary education teacher's portfolio; children's supplementary education; objectives; functions; structure; the principles of designing the supplementary education teacher's portfolio.

\section{Introduction}

The changes occurring in Russia nowadays resulted in the new requirements to the system of supplementary education. There is an objective to improve the quality of the supplementary education services through the variety of the curricula, meeting both the needs and interests of each child, and the society in general. Today the professional activity of a supplementary education teacher shall be aimed at creating all the conditions in the pedagogical process for children's education, development and self-development as well as to select the better options for self-expression (Seryakova, 2005). There is a necessity in modern means of supplementary education teacher's activity quality evaluation, presentation of their achievements and results in different areas of their practical activities. A portfolio can be one of these 
means.

The necessity and possibility to use the supplementary education teacher's portfolio is caused by the necessity to settle the following contradictions:

- between the values of education humanistic paradigm and the formal approach in evaluating the quality of the supplementary education teacher's activity;

- between the outdate system of the supplementary education teacher's activity evaluation in the institutions and the modern requirements to the system of supplementary education and the quality of the educational services rendered (Loginova, 2008);

- between the need in innovations to the staff management of the supplementary education institutions and the lack of the adequate form of the work with the supplementary education teachers.

A supplementary education teacher's portfolio - is the technology of actual achievements' definition, accumulation registration, classification, assessment, as well as presentation of the results of educational, diagnostic, methodic, research, self -educational, social and other activities of the supplementary education teacher within a certain period of time, displaying the availability of the educator for self-actualization and self-development.

The objectives of the supplementary education teacher's portfolio are like follows: to motivate teachers to improve the quality of the professional activity and design the individual strategy of the personal and professional development; to monitor the quality of the supplementary education teacher's professional activity; to create a healthy competitive environment, determining the conditions for an effective professional career; to ensure impartiality, periodicity, openness of the teacher's activity assessment, to ensure efficient certification of teachers; to develop the skills of reflexive and evaluation activities. (Tregubova, Sahieva, Masalimova, 2008).

The main functions of the supplementary education teacher's portfolio are like follows: motivational-presentation increases motivation to the professional activity allowing the teacher to provide its results in dynamics; educationalforming - contributes to the acquisition of new knowledge, development of the existing competencies, formation of the new ones, development of creative activity; projective-simulating - helps to design one's own model of the individual educational route and professional development; reflexive-evaluating - allows overall integrative assessment of the educational, professional, personal and other achievements of the teacher, of common cultural and professional competencies development level, provides the opportunity to develop skills in reflective and evaluative activities (Sahieva, 2011).

\section{Literature Review}

The problems of children's supplementary education organization and development were considered in the works of A.G. Asmolov (1997), V.A. Berezina (2007), L.N. Builova, N.V. Klenova (2005).

The works of Z.A Kargina (2009), B.V. Kupriyanov (2009), S.A. Pisareva (2003) are dedicated to the practical aspects of the supplementary education teacher's under current conditions.

The issue of the portfolio to be used in the educational work is disclosed in the works of the following domestic researchers: L.P. Makarova (2010), M.A. Pinskaya (2009), M.M. Potashnik (2009), L.A. Pronina (2009), V.K. Zagvozdkin (2010).

The numbers of foreign researchers have devoted their work to the problem of portfolio: D. Baume (2001), J.E. Jones (1994), M. Kimball (2002), F.L. Paulson, P.R. Paulson, C.A. Meyer (1991).

However, currently the problem of portfolio design and use by the supplementary education teacher is an insufficiently investigated area of theoretical and practical knowledge.

\section{Methodological Framework}

The framework of the supplementary education teacher's portfolio is made of the following design principles:

- competency building approach (assessment as per the teacher's activity results);

- comprehensiveness (comprehensive assessment with the different forms of activity results' presentation (documents, works, references, expert assessments and etc..);

- $\quad$ authenticity (conformity of the material provided with the actual status);

- continuity (the material provided shall reflect the dynamics of the teacher's activity broadening, the professional growth);

- optimality (development of the portfolio is not a goal in itself, it shall facilitate the improvement of the professional activity, development of the common cultural and professional capacity). 


\section{Results and Discussions}

Developing the teacher's portfolio structure one should keep in mind that it can vary depending on the goals set, the institution's specifics, professional activity of the teacher and some other factors.

\subsection{Supplementary education teacher's portfolio structure}

\section{Explanatory note/introduction}

where in a free form one should specify which materials are included into the portfolio and give proof that these materials are the evidence of the teacher's professionalism and competence.

Section 1. General information on supplementary education teacher

1.1 Curriculum vitae

2.2 Autobiography

Note. The copies of the confirming documents (the copy of diploma on the basic professional education, the copies of the qualification documents, document on honors and government awards) can be attached at the end of the section.

Section 2. Educational work

2.1. Educational creed/ Educational essay/ Educational philosophy/ Educational concept (depending on the teacher's experience in the educational field)

2.2 Implemented curriculum or educational project that brings together several curricula (information on the programs' expertise, if any)

2.3 Course schedule

2.4 Program for work with gifted children

2.5 Technologies, methods and techniques used

2.6 Information on the demo lessons and master classes performed (№ , date, subject, group, level)

Note. The best lecture notes/demo lessons and master classes plans (for the last 5 years or from the last certification); copies of the lessons's analysis, masterclasses of the methodical association's Manager, management, expert committee members, and the self-analysis of the lessons conducted can be arranged at the end of the Section.

Section 3. Educational process monitoring

3.1. Monitoring of the educational program perception by the trainees

3.2 Information on the enrollment by year

3.3 Monitoring of the trainees' personal qualities, abilities, general cultural level and good manners development

3.4. Results of pupils' participation in contests, festivals, concerts, academic competitions, competitions, exhibitions and etc. (№, date, name, group, level, organizers, results)

3.5 Continuity of education (information on the trainees' entrance to industry-specific colleges or other higher educational institutions) (№, year, name of the pupils, full name of the educational institution, specialty/major)

Section 4. Methodological activity

4.1. Methodological subject (№, subject, term, expected and actual results (intermediate, final)

4.2. Methodological support of the educational program (№, name, type (designs, study- guides, practical suggestions, instructions, instructional designs, training hand-outs and etc.), the date of creation, annotation, form (printed, handwritten, audiovisual, computer, etc; if printed, the output data is issued according to requirements of GOST), volume in sheets (s.) and printed sheets (p.s.), circulation, co-authors, the method of distribution (available in the methodical office, available on web-site, Internet, publication)). One can provide the reviews for the study-guides, designs and etc.

4.3 Information on public speaking at creative team meetings, methodological associations, professional associations and communities, teachers council, meetings, methodological workshops, conferences of different levels (institution level, district, municipal, republican, all-Russian, international) on the methodological subject or problem (№, date, address subject, organizers, location, level)

Note. The summaries of the public speaking at the methodological workshops are attached.

4.4. Leadership of the methodological association, taskforce on the actual subject, tutorship (assistance to young colleagues, assistance in the further certification of the colleagues, assistance in portfolio designing and etc.)

Section 5. Innovative, research, experimental activities

5.1 Information about writing a thesis (diploma) work/master thesis (for new teachers) (the date of defense, subject, thesis supervisor, name of the educational institution, specialty/major), 
Information about writing a thesis (diploma) during professional retraining (the date of defense, subject, thesis supervisor, name of the educational institution, specialty/major),

Information on Master thesis/Doctoral thesis/thesis (the date of defense, subject, stages of writing, scientific advisor, specialty, leading company)

5.2 Information on research, experimental activities (№, date/terms, subject/range of problems, objectives, scientific advisor land (Name, degree, title, job), the results of the research, experimental activities, reporting form)

5.3 Information on participation in Overseas Research Students Awards (№, date/terms, name/grant subject, objectives, organizers, form of participation, level, results, reporting form)

5.4 Information on public speaking at Research and Practice Seminars, conferences of different levels on the subjects of research and experimental activities (№, date, speech subject, organizers, location, level)

Note. Best speech summaries at Research and Practice Seminars, conferences are attached.

5.5 The list of scientific publications (№, name, type (concept, monograph, article, theses and etc.), output data, volume in sheets and printed sheets, circulation, co-authors)

5.6 Information on own site creation or the site of children/teenager group, professional blog or weblog running and etc.

Section 6. Educational and social activities

6.1 Information on participation in the social activity (social movements, funds, actions, elections of different levels, development of socially-minded projects, programs, social initiatives and etc.) (№, type, organizers, date, level)

6.2 Information on the volunteer and charitable activities (charitable actions and actions for disabled children, orphans, the children of migrants, senior citizens, war and labour veterans and other voluntary initiatives)

6.3 Arrangement of work in children's educational institutions, schools, grammar schools, lyceums, other educational institutions, voluntary and etc.

6.4 Arrangement of work with pupils' parents and supervising teachers

6.5 Arrangement of educational and leisure activities (№, date, name of the event, form (tour, discussion, exhibition, poetry/music session, festive events and etc.), participants, level).

The best summaries of educational and leisure activities shall be attached.

6.6 Arrangement of health-improving and sporting activities (№ , date, name of the activity, form of presentation (hikes, relay races, marathons, competition, sports events, Health day and etc.), participants, level).

The best summaries of health-improving and sporting activities shall be attached.

Section 7. Information on self-education, skills upgrading, professional retraining

7.1. Individual self-educational program, including goals, objectives, content, self-educational activity (№, subject/problem/self-educational program, terms, expected and actual results (intermediate, final))

7.2. Information on reciprocal visiting of classes (№, date, subject, name of the teacher whose class you visited, form, group, brief analysis)

7.3. Information on participation (without public speaking) in the methodological associations of the different levels (№, date, themes, organizers, location, level, status (listener, discussant of the declared issues)

7.4. Information on participation (without public speaking or publication) in seminars, conferences and etc. of the different level (№,date, themes, organizers, location, level, status (listener, discussant of the declared issues). Here one can submit the programs of seminars, conferences.

7.5. The list of reviewed psychology, pedagogical and methodic literature and etc. by year with annotation (№, year, book title, author/s, publisher imprint, blurb)

7.6 The list of electronic educational and self-educational resources (licensed and independently created)

7.7. Information on qualification upgrading courses (date, subject/range of problems, location, institution/organizers, number of hours, the issued document, registration number). Copies of licenses, certificates, reference on qualification upgrading courses are attached.

7.8. Information on professional retraining (date, location, organizers number of hours, (specialty)/major (profile), subject of the graduation thesis, document, registration number). The copy of the diploma on professional retraining is attached.

7.9 Information on the postgraduate, doctoral or PhD studies.

Section 8. Self analysis of the professional activity

Self-analysis and self-assessment of the educational, diagnostic, methodical, innovative, research, experimental, self-educational, social and other activities, formed and developed competencies, experience in the creative activities, growth in the self-educational competence, written in a free form.

Section 9 . The strategy of further self-development 
In this section the teacher determines the plans for the future, the further ways of self-improvement, selfdevelopment, which is particularly topical in the new paradigm of advancement of education «education throughout life».

Note: information provided in the section shall be specific. For instance,

1. Participation in theoretical and practical conference «Psychological-pedagogic support of the educational process in the institutions of the supplementary education» - March 25, 2015.

2. Open lesson «Decorative-applied art» - April, 162015.

3. Participation in theoretical and practical conference « Supplementary education of children and young people: development strategy» with the report/thesis «Supplementary education of children and young people development tendencies within Russian and abroad», as well as publication of the report/thesis - May 25, 2015.

4. Training of the pupils for the district competition (name of the competition, location) - October 10, 2015 and etc.

8. Development of common cultural and professional competencies, self-educational competency (lifelong)

Section 10. Professional achievements

10.1. Participation in the professional competitions, amateur festivals, exhibitions and etc. (№, date, name, organizers, location, level, results)

10.2. Information on awards and rewards (№, effective date, name of award/reward, who awarded, the reason for award)

10.3 Information on publications regarding the professional activity of the educator in mass media, information on the TV spots and etc. (№, date, name of the publication/TV spot, summary of the publication/TV spot, newspaper/channel). One can provide copies of the publications in mass media, pictures of TV spots and etc.

Copies of confirming documents (certificates, diploma, certificate of appreciation for the participation in professional skills competitions, amateur festivals, exhibitions, document on awards and rewards) are attached.

Note: 1) Management, Head of methodical association, members of Certification Committee can select mandatory sections and points in the proposed structure of the portfolio of the supplementary education teacher, include additional sections and points, according to the target of the portfolio and the certification requirements; 2 ) the teacher can at his own choice include some additional sections and points into the portfolio, reflecting the professional activity, its specifics, tendency and the individual style.

\subsection{Some alternatives to use the portfolio of the supplementary education teacher}

To collect and systemize the material between the certification periods, during the certification that will allow to present creative skills along with analysis and self-evaluation of the teacher's work and also to extend boundaries of personal and professional collaboration and cooperation, which will significantly increase the importance of the certification procedures; for self-evaluation and defining the perspective of professional growth; for filling the vacant positions; for occupational change-over.

\subsection{Some risks of the portfolio implementation}

Rejection of the certification form by some educators, since portfolio compilation is time-consuming process; inability to design portfolio; unstructured work with portfolio; inclusion of the unproven material.

\subsection{Practical recommendations to design portfolio}

Each section should be dedicated to a certain type of activity of the teacher; every portfolio element should be with the date in order to trace the dynamics of the teacher's professional growth and should be signed by the author, developer, compiler; it's preferable for the portfolio to include the confirming photos; it's reasonable to include the material within the period between the certifications (from the last certification); if the author of portfolio makes complete electronic version it may be supported with different short audio and video records (fragment of the class video-record, of activity, public speaking), electronic versions of the works and etc.; it's reasonable to use two types of portfolio: working, containing all the material available; evaluative (demonstrative), which selects the materials reflecting fully the achievements, the results of the professional activity of the teacher and the progress in the personal and occupational growth.

\section{Conclusion}

Thus, the portfolio will allow a supplementary education teacher the following: to present the practical experience, the 
results of the different professional activities; extend the boundaries of personal and professional interaction and cooperation; trace the dynamics of professional growth and development; develop the ability to analyze and evaluate own activity, compare it with common standards and on this basis correct and improve it; design and implement the individual route and the programs of the professional growth.

Portfolio will allow the management of supplementary educational institution the following: monitor the quality of the teachers' professional activities; define the perspectives for teachers training and professional growth; perform efficient certification of supplementary education teachers; form a healthy competitive environment, determining the conditions for professional career; ensure impartiality and openness of ethical and material incentives of teachers.

\section{References}

Asmolov, A.G. (1997). Supplementary education as the zone of proximal development of education in Russia: from traditional pedagogy to pedagogy development. Vneshkolnik, 9, 6-8.

Baume, D. (2001). A briefing on assessment of portfolio. York: Learning and Teaching Support Network (LTSN). Generic Centre, 27.

Berezina, V.A. (2007). Supplementary education of children in the Russian education system. Moscow, 157.

Builova, L.N., Klenova, N.V. (2005). How to organize supplementary education of children in school. M.: ARKTI, 288.

Jones, J.E. (1994). Portfolio assessment as a strategy for self-direction. Learning. New Directions for Adult and Continuing Education, $64,23-29$.

Kargina, Z.A. (2009). A practical guide for teacher of supplementary education. Moscow, 96.

Kimball, M. (2002). The Web Portfolio Guide: Creating Electronic Portfolios for the Web. Texas Tech University: Longman, 208.

Kupriyanov, B.V. (2009). Teacher of supplementary education: anatomy of professional activity. Supplementary education and upbringing, $12,3-7$.

Loginova, L.G. (2008). The quality of supplementary education for children. Management. Moscow: Megapolis, 120.

Makarova, L.P. (2010). Teacher`s Portfolio. Volgograd: Teacher, 102.

Paulson, F.L., Paulson, P.R., Meyer, C.A. (1991). What makes a portfolio a portfolio? Educational Leadership, February, 60-63.

Pinskaya, M.A. (2009). Teacher`s Portfolio. Moscow: Chistye Prudy, 32.

Pisareva, S.A. (2003). Modern scientific research in the field of supplementary education: possible use in the practice of the teacher. St. Petersburg, 157.

Potashnik, M.M. (2009). Teacher`s Portfolio: possible benefits and possible harm. Education, 6, 99-103.

Pronina, L.A. (2009). Teacher`s Portfolio. Pupils` Upbringing, 4, 15-20.

Sakhieva, R.G. (2011). Vocational school student` portfolio. Kazan: Academy of Social Education, 33.

Seryakova, S.B. (2005). Psychological-pedagogic competence of the teacher of supplementary education. Moscow: Moscow State Pedagogical University, 112.

Tregubova, T.M., Sakhieva R.G., Masalimova A.R., Beljakin A.M. and Tazutdinova E.H. (2008). Academic mobility of students in higher education: national and international experience of its formation. Kazan: Fatherland, 131.

Zagvozdkin, V.K. (2010). Traditional and modern forms of teacher evaluation and their effectiveness. Head teacher, 6, 52-57. 